\title{
Exploring Factors Contributing to Recidivism: The Case of Dessie and Woldiya Correctional Centers
}

\author{
Goche Tegeng and Hayelom Abadi* \\ Department of Psychology, Wollo University, Dessie, Ethiopia
}

\begin{abstract}
The primary objective of this study is to explore the contributing factors for recidivism in Dessie and Woldia correctional centers, North East Ethiopia. To achieve the aim of this study, a mixed research design was employed. The quantitative data from the recidivists were analyzed by using descriptive statistics while the qualitative data analyzed by using thematic analysis. The major factors that contributes for recidivism were economic problems (i.e. poverty, unemployment, poor living conditions), family problems (family conflict, lack of love and affection, lack of close supervision, divorce, death of one or both parents) and psychological problems (anxiety, depression, addiction, aggressive personality traits). Moreover, the study reveals that labelling, discrimination, false Witness, lack of adequate rehabilitation and reintegration services are the main factors for recidivism. Finally, the prison centers and other stakeholders should provide sufficient rehabilitation and reintegration services for recidivists.
\end{abstract}

Keywords: Addiction; Crime; Discrimination; Labeling; Poverty; Rehabilitation; Reintegration; Unemployment

\section{Introduction}

Recidivism is "one of the most fundamental concepts in criminal justice" and relevant in understanding the core functions of the criminal justice system such as incapacitation, deterrence, and rehabilitation [1]. Within criminal justice agencies, the level of recidivism is an important outcome variable that provides the basis for determining the extent to which an agency has been able to effectively intervene in the criminality of the offender populations it serves, identifying the needs for more effective programs, communicating the need for increased resources, and demonstrating accountability to the public and to legislators [2]. There are many different plausible contributing factors that might explain why released offenders could not successfully reenter the community. A notable number of studies examined the contributing factors to recidivism among released offenders. The most plausible reasons to explain the relatively high recidivism rate among released offenders were centered on the offenders' educational illiteracy, lack of vocational job skills, lack of interpersonal skills, or criminal history. Besides, socio-economic factors such as gender, age and employment status influence the possibility of committing crimes after first conviction. In terms of gender, men are more likely to return to prison because of criminal peer associations, carrying weapons, alcohol abuse, and aggressive feelings [3]. According to United States Sentencing commission 24.3 and 13.7 percent of males and females were recidivates respectively in USA. Age is also another demographic determinant factor for recidivism. A study in USA shows that recidivism rates decline relatively consistently as age increases. So youths are more likely to offend than older people. Among all offenders under age 21 , the recidivism rate is 35.5 percent, while offenders over age 50 have a recidivism rate of 9.5 percent (United States Sentencing commission, 2004). Therefore, incarceration, particularly at a young age, can lead to an accumulation of disadvantages over the life course, with future opportunities severely restricted [4]. On the other hand, the absence of employment is a consistent factor in recidivism and parole or probation violations, and having a criminal history limits employment opportunities and depresses wages. In New York State, labor statistics show that $89 \%$ of formerly incarcerated people who violate the terms of their probation or parole are unemployed at the time of violation. Further research suggests that 1 year after release, up to $60 \%$ of former inmates are not employed. Nationally, according to a study by Bushway and Reuter [5], one in three incarcerated people reported being unemployed before entering state prison, and fewer than half had a job lined up before release.

Moreover, family is another main factor in the formation of individual and social personally of the child. From the child's point of view, parents are the most important and most valuable models of the universe. Prisoners' recidivism rates are associated with the amount of contact they receive with their families [6]. Less care of family to their children [7] and lack of family involvement is strongly related to crime and incarceration rates. In line with this, studies in Australia revealed that, offenders with limited family support or attachment are more likely to reoffend. Alongside, drugs problem is one of the main headline crime stories of our times which leads to crime. The urge to commit crimes by drug addicts and alcoholics is motivated by the desire to support their habits. Much of these offenders' behavior can be linked to substance abuse and addictions (UNODC, 2012). Because they tend to serve short-term sentences, their access to treatment and other programmers while in detention is quite limited and they remain at high risk of reoffending.

The issue crime in general and recidivism in particular has attracted the interest of some researchers in Ethiopia. These studies were basically focused on criminal behavior; juvenile delinquency and the criminal justice system i.e. have tried to point out from legal perspectives. Yet the amount of researches and the knowledge obtained from those researches do not suffice to explain the extent and depth of the problem related to recidivism rather they try to highlight the issue from criminal behavior. Andargachew [8] in his book "The Crime Problem and Its Correction" found that Ethiopian prisons are suffered from over crowdedness, lack of sanitation, and insufficient amount and

*Corresponding author: Abadi H, Department of Sociology, Wollo University Dessie, Ethiopia, Tel: +251-919-472-925; E-mail: abadihayelom129@gmail.com

Received July 04, 2018; Accepted July 26, 2018; Published July 31, 2018

Citation: Tegeng G, Abadi H (2018) Exploring Factors Contributing to Recidivism: The Case of Dessie and Woldiya Correctional Centers. Arts Social Sci J 9: 384 doi: 10.4172/2151-6200.1000384

Copyright: (c) 2018 Tegeng G, et al. This is an open-access article distributed under the terms of the Creative Commons Attribution License, which permits unrestricted use, distribution, and reproduction in any medium, provided the original author and source are credited. 
quality of food service. He has also focused the history of Ethiopian police force as well as the history of judicial system in Ethiopia. However, Andargachew failed address the issue of recidivism and lack of rehabilitation on repeat offenders. Daniel [9] also studied Crime incidences in Addis Ababa with an emphasis on the nature, spatial pattern, causes, consequences and possible remedies and showed different variables causing criminal behavior. But he too failed to identify the major causes of recidivism. Nayak [10] studies magnitude and impact Juvenile Delinquency in Gondar, explored that Juveniles who were from large sized /or disintegrated family commit delinquent act than smaller sized and healthy family. It has a greater impact on different levels like, individual, family, community and society at large. Yet, he also lacked from discussing recidivism. In addition to this, Meti [11] in his/her study in Addis Ababa tried analyze the influence of socio economic factors on crime with particular emphasis on the triggering factors that prompt criminal behavior is a timely endeavor. But he still refrained from explaining the factors contributing to recidivism. On top of that, methodologically, the aforementioned studies gave a huge emphasis on quantitative method in the understanding of crime and criminal behavior, for the sake of describing socio-economic and demographic characteristics of study participants' vis-à-vis recidivism. On the contrary, in the present study attempt has made to incorporate qualitative method intensively due to the fact that lived experience of recidivists are more understandable through a detailed and rich data that could be collected by giving more attention to qualitative method.

However, as the foregoing discussion has shown, researches so far conducted have put too small price on the problem of recidivism. Thus, this study aims at filling this gap by studying the factors contributing to recidivism in the case of south Wollo and North Wollo correctional centers specifically Dessie and Woldiya.

\section{Research Methods}

\section{Description of the study area}

Dessie city was founded in 1882 . It is located in northern part of Ethiopia in Amhara National Regional State, South Wello Zone at a distance of $400 \mathrm{~km}$ from Addis Ababa. Its astronomical location is $11^{\circ} 08^{\prime}$ North Latitude and $39^{\circ} 38^{\prime}$ East Longitude. Dessie is one of the reform towns in the region and has a city administration consisting of municipality and 10 urban and six rural kebelles [12]. According to Central Statistical Authority projection in 2011, the population of the town was 131,640 . Out of this 57,728 (44\%) were males and 73,912 $(56 \%)$ were females. The population growth rate at medium variant was $3.2 \%$ while household size in the town is calculated to be 4.2 . On the other hand, Woldia town is located in Amhara National Regional State, North Wollo Zone at a Distance of $521 \mathrm{~km}$ from Addis Ababa. It is one of the reform towns in the region and has a city administration, municipality and three kebelles. According to the National Population and Housing Census carried out in 2007, the population of the town was 60,544 in 2012 . Out of this 22,990 were males and 23,136 were females. Regarding age distribution 19,666 (32.48\%) were within the age group of 0 - 15 years, 23,730 (39.19\%) $16-60$ years and 2,730 (4.51\%) 60 years and above. The population growth rate of the town with medium variant is $4.86 \%$ while the average household size is calculated to be 3.4 [13].

\section{Study design}

The study was intended to explore the factors contributing to recidivism south wollo and north Wollo zone correctional administration pecifically Dessie and Woldiya. In doing so, a crosssectional study design was employed. This design enables the researcher to study the population at a particular point in time. All over the study, the researcher used mixed methods to get detail and diverse information on a single study. In this research, the quantitative part aimed at complementing (augmenting) the finding of the qualitative data. According to Creswell [14], in this design the investigator was collected both forms of data (quantitative and qualitative) at the same time during the study and then integrates the information in the interpretation of the overall results in order to provide a comprehensive analysis of the research problem. The objective of the research is not address with single method quantitative or qualitative rather it needs the integration of the two methods to answer questions that cannot be answered by qualitative or quantitative approaches alone. Therefore, the triangulation of quantitative and qualitative methods helps to supplement each other.

\section{Study population, sample size and sampling}

Study participants were composed of both men and women recidivists, prison officers, counselors and head of the prison. The study participants were recruited by employing both probability and non-probability sampling designs. Probability sampling was used to select the recidivists. Thus, 107 recidivists were selected based on comprehensive sampling techniques. Due to its slight number of recidivists the researcher was used comprehensive sampling techniques. On the other hand, the informants of qualitative research were recruited by using purposive sampling technique. Thus, eleven in-depth-interviews with recidivists were conducted. Moreover, key informant interview had been made with two counselors, six police officers and four prison administrators. In addition, three FGDs had been made.

\section{Methods of data collection}

Three main methods of data collection were employed. These are Survey, in-depth interview and Key informant interviews.

\section{Sample survey}

Survey method is one of the most widely used primary data gathering methods in social research. This method enables researchers to study a given population by relaying only in the portion of that population which is called samples. Thus, it saves time and economy, again access accurate information. Accordingly, in this study the researchers selected 107 recidivists from the two prisons based on compressive sampling.

The data will be collected by using close-ended and open-ended questionnaires. The researcher prepared questionnaire in accordance with the research objectives. The entire questionnaire prepared in English for the first time afterward it was translated in to Amharic language in the intention that the majority of the informants are Amharic speakers.

In addition to, the preparation of the questionnaire, the survey administered by two enumerators for the reason that all recidivists may not read and write. Then, the researcher given one day training for the enumerators to perform their job well and to have clear understanding about the questions put in the schedule. The training includes how the enumerator conducted the survey and the way filling the questions. Besides, it includes further explanation and discussion on the questions to make clear to the enumerators. Finally, the enumerators administered the questionnaires under the supervision of the researcher.

\section{In-depth interview}

In-depth interviewing is the most commonly used data collection 
approach in qualitative research. In-depth interviews are those interviews that are designed to discover underlying motives and desires. Such interviews are held to explore needs, desires and feelings of respondents [15]. This method enabled the researcher to generate highly detailed information and to have better understanding on factors contributing to recidivism in south wollo and north Wollo zone correctional administration specifically Dessie and Woldiya. In doing so, in-depth interview is conducted with ten male recidivists and one woman from Wodiya correctional center with the help of interview guide check lists. The selected recidivists provided detail information about their criminal profiles, factors behind their re-offending, their post-prison experiences, rehabilitation related issues and their socioeconomic background. To conclude, the recidivists were selected based on their frequency of re offending.

\section{Key informant interview}

Key informant interview is used to collect qualitative data from informants that have knowledge and experience on the issue of crime in general and recidivism in particular. This enabled to get in-depth information from informants. Interview guide with loosely structured conversation is used to collect data. This allows the interviewee to respond flexibly and the interviewer to manage the core issues of the study. Subsequent to that the researcher asked the informants about their consent to take part the interview. Following the agreement of the informants to take part in the conversation, the researcher was held an interview by introducing the purpose and the ultimate use of the information to the informants. In this study, two counselors, six police officers and four prison administrators were selected purposively and interviewed.

\section{Methods of data analysis}

The data obtained from various sources is analyzed using both quantitative and qualitative data analysis methods. The qualitative data was collected from respondent using key informant and in depth interview. Qualitative data analysis is conducted concurrently with gathering data, making interpretations, and writing reports [14]. The researcher listen to all audio taped and read the field notes step by step to jot down all the information. After that the audio taped from key informant interview and in depth interview transcribed verbatim, and translate from Amharic to English. Then, the translated data is organized, prepared, and broken up into sections based on their themes. Then a technique of thematic analysis is used to interpret and make sense of the organized data.

On the other hand, the quantitative data was processed as an important part of the whole survey operation. It includes editing, coding, data entry, data cleaning and consistency checking. A Statistical Package for Social Sciences (SPSS, version 20) was used to analyze the data. The researcher used descriptive statistical tools to analyze the quantitative data. Descriptive tools such as frequency, percentages, and graphs are employed to present the results. Finally, the quantitative findings are used to substantiate the qualitative findings.

\section{Ethical consideration}

In the progress of research, researchers need to respect the participants and the sites for research [14]. Thus, due respect was given to the participants during the data collection process. Besides, an informed consent was received from participants before the commencement of the interviews to ensure that participation in research was voluntary. Respondents were informed that they have the right to participate voluntarily and withdraw from the research at any time. Anonymity of respondents and confidentiality of their responses were ensured throughout the research process. Information that was provided by informants would not be transferred to a third party or would not be used for any other purpose.

\section{Results}

This chapter presents the results of the study in line with the research questions. Furthermore, the major findings of the study, based on the data obtained through comprehensive sampling survey; in-depth and key informant interview are presented, in a descriptive rhetoric. Theories relevant to the underlying themes and related literatures are used to interpret the primary data.

\section{Demographic characteristics of respondents}

The subjects involved in this study were recidivists and prison officials from Dessie and Woldia correctional centers. The total numbers of recidivists from both correctional centers were 60 and 47 respectively. However, among these 107 recidivists, 3 participants didn't return their questionnaire. Hence the analysis was performed using data from 104 recidivists.

As shown in Table 1, from a total of 104 recidivists $100(96.2 \%)$ were males and $4(3.8 \%)$ were females. In addition to this, $71(69.6 \%)$ of the respondents came from urban areas while the remaining 31 (30.4\%) of the respondents were from rural areas. With respect to age, the respondents' age ranged from 16 years to 64 years with the mean age of 24.27 years. With regard to their educational level, $27(26.0 \%)$ of the respondents were illiterate. In addition to this, 17 (16.3\%), $27(26.0 \%)$ and 30 (28.8\%) of the respondents were learned from 1-5, 5-8 and 9-12 grade respectively. With respect to their marital status, the majority of respondents (76 (74.5\%) were married. The remaining $21(20.6 \%)$ and $5(4.9 \%)$ of the respondents were single and divorced respectively. Another important indicator for understanding the socioeconomic status is the monthly income of the respondents. Accordingly, 49 $(47.1 \%)$ and $34(32.7 \%)$ of the respondents had a monthly income of below 500 birr and between 500 and 1000 birr respectively.

\section{The rate of reoffending and types of crime committed by re- cidivists}

As Table 2 revealed that the majority 71 (68.3\%) of the respondents were reoffend two times, $23(22.1 \%)$ were reoffend three times and 8 (7.7\%) were reoffend four times. The remaining 2 (1.9) were reoffend more than five times. To understand the factors that contribute to recidivist behavior, it is important first understand the different forms of recidivist behavior of study. Accordingly, 61 (58.1\%) of the respondents were convicted because of theft. In addition to this, assault is the second type of crime which is reported by $19.2 \%$ of the respondents. Surprisingly, this study found that most of the recidivists were convicted by the same crime at the second, third and fourth time. Similarly, the qualitative data also revealed the different kinds of crimes that were committed by criminal recidivists. According to the participants, the most common types of crime committed by recidivists are property crime like theft, burglary and fraud. The second type of crime that was committed by recidivists was assault and bullying. In line with this idea, it is important to narrate the criminal profile and history of some recidivists. For instance, one recidivist has narrated his lived experience as follows: I had imprisoned for three times. All of the three charges are in theft cases but I did not commit the first and the second crimes. I was imprisoned in false witness. I only committed the third one. However, I have imprisoned around two years for all of the three cases [18 years old informant from Dessie correctional center]. 


\begin{tabular}{|c|c|c|c|}
\hline \multirow{2}{*}{ Variable } & \multirow{2}{*}{ Alternatives } & \multicolumn{2}{|c|}{ Response $(\mathrm{N}=104)$} \\
\hline & & Frequency & Percentage \\
\hline \multirow{3}{*}{ Sex } & Male & 100 & 96.2 \\
\hline & Female & 4 & 3.8 \\
\hline & Total & 104 & 100 \\
\hline \multirow{4}{*}{ Age } & $16-29$ & 84 & 80.7 \\
\hline & $30-43$ & 13 & 12.5 \\
\hline & Above & 3 & 3 \\
\hline & Total & 100 & 96.2 \\
\hline \multirow{3}{*}{ Area they came from } & Rural & 31 & 30.4 \\
\hline & Urban & 71 & 69.6 \\
\hline & Total & 102 & 100 \\
\hline \multirow{7}{*}{ Educational level } & Illiterate & 27 & 26 \\
\hline & 1-4 grade & 17 & 16.3 \\
\hline & $5-8$ grade & 27 & 26 \\
\hline & $9-12$ grade & 30 & 28.8 \\
\hline & certificate/diploma & 2 & 1.9 \\
\hline & Degree & 1 & 1 \\
\hline & Total & 104 & 100 \\
\hline \multirow{4}{*}{ Marital status } & Married & 76 & 74.5 \\
\hline & Single & 21 & 20.6 \\
\hline & Divorced & 5 & 4.9 \\
\hline & Total & 102 & 100 \\
\hline \multirow{5}{*}{ Monthly income } & below 500 birr & 49 & 47.1 \\
\hline & 500-1000 birr & 34 & 32.7 \\
\hline & 1000-2000 birr & 13 & 12.5 \\
\hline & above 2000 birr & 8 & 7.7 \\
\hline & Total & 104 & 100 \\
\hline
\end{tabular}

Table 1: Percentage distribution of sex, age, residential status, educational level, marital status and income of respondents at Dessie and Woldiya correctional centers.

\begin{tabular}{|c|c|c|c|c|c|}
\hline $\begin{array}{l}\text { Rate of Re } \\
\text { offending }\end{array}$ & Frequency & Percentage & $\begin{array}{l}\text { Types of } \\
\text { crime }\end{array}$ & Frequency & Percentage \\
\hline \multirow{2}{*}{ Twice } & \multirow{2}{*}{71} & \multirow{2}{*}{68.3} & Theft & 61 & 58.7 \\
\hline & & & Robbers & 4 & 3.8 \\
\hline \multirow{2}{*}{ Three Times } & \multirow{2}{*}{23} & \multirow{2}{*}{22.1} & Burglary & 1 & 1 \\
\hline & & & Fraud & 8 & 7.7 \\
\hline \multirow[t]{2}{*}{ Four Times } & \multirow[t]{2}{*}{8} & \multirow[t]{2}{*}{7.7} & $\begin{array}{c}\text { Sexual } \\
\text { offenses }\end{array}$ & 3 & 2.9 \\
\hline & & & Homicide & 3 & 2.9 \\
\hline \multirow{2}{*}{$\begin{array}{l}\text { Five times } \\
\text { and above }\end{array}$} & \multirow[t]{2}{*}{2} & \multirow[t]{2}{*}{1.9} & $\begin{array}{l}\text { Burning } \\
\text { house }\end{array}$ & 2 & 1.9 \\
\hline & & & Assault & 20 & 19.2 \\
\hline \multirow[t]{2}{*}{ Total } & \multirow[t]{2}{*}{104} & \multirow[t]{2}{*}{100} & $\begin{array}{l}\text { Specify } \\
\text { others }\end{array}$ & 2 & 1.9 \\
\hline & & & Total & 104 & 100 \\
\hline
\end{tabular}

Table 2: The frequency of re offending and types of crime committed by recidivists at Dessie and Wodiya correctional centers.

Similarly another interviewee said that "I imprisoned three times. The first imprisonment attributed to illegal political campaign of the 1997 election but I was not involved in any political campaign. The second and the third cases for imprisonment were fraud and conflict with community police officers respectively [33 years old informant from Dessie correctional center]".

On the other hand, some of the participants also committed violent crime such as assault. One of the interviewee said that " $I$ committed violent crimes more than six times. Most of the crimes that
I was committed are related to fighting and bulling. I used knife in the commission of an offense. I have stabbing three persons by using knife [34 years old informant from Dessie correctional center]".

\section{The impact of economic problems and its contribution to re- cidivism}

Economic or material deprivation is one among the factors that throw in to crime. This also considered as factors for re-offending. The economic problems of the participants were manifested in the form of unemployment, poverty and lack of income which leads people to engage in criminal activities repeatedly.

In this study, an attempt was made to explore whether unemployment and economic factors are the causes of recidivism. Thus, recidivists were asked about these issues. As it is shown in Table 3 above, 59 (57.3\%) of the respondents were unemployed before their imprisonment. This shows that a great deal of recidivists were unemployed. Besides, 58 (56.3\%) of the respondents believed that unemployment was the causes of re-offending. In line with this, the qualitative data from participants also revealed that economic problems like poverty, lack of income and unemployment were the main causes of re offending. Almost all of the prisoners have been frequently portrayed as economically poor and unemployed. They have not got any job in the post-release periods. In supporting this idea, one of the respondent said that "I was released from prison but it is difficult to find employment because of my criminal background". Hence, the recidivist criminal history is one of the deterring factors to find a job. The suspicion and fear of employers to hire those with a criminal record are the causes of unemployment for most recidivists. The absence of jobs in the post release periods compelled for the majority offenders to involve in a certain criminal activities as alternatives mechanism to secure their financial gains.

The other contributing factors to recidivism were the negative attitude of the community in general and the state administrators in particular towards recidivists. Inmates in the post release period were segregated from every economic opportunity. They were prohibited from getting any financial assistance/loans to work in group/association. The social environment is not suitable to engage in any income generating activities. No one was volunteered to give start-up business. In general, inmates in the post release periods were not trusted by the community even though they rehabilitated and changed their behaviors. This condition compelled them to enter into criminal activities. Besides, the recidivists were asked if they have enough income after imprisonment to fulfill their basic necessities. The majority of respondents $(79.81 \%)$ reported that they did not have enough income to satisfy their basic necessities. Consequently, 55 (59.8\%) of the respondents admitted that economic problems contributed to their reoffending. In this respect, one of the re offender described his experience as follows:

I have taken vocational training on metal works inside the prison, however, I did not get any work upon release. The government could not provide any job opportunities. There is no any financial support given for us upon release to establish new business. I do not have any money to sustain my life so I have repeatedly engaged in theft crimes. Due to this, I have imprisoned many times and I become hopeless. This forced me to engage again in crime.

As Table 4 shows 44 (44.4\%) of the respondents reported that one of their parent (either mother or father) are died. In addition to this, 43 (43.4\%) of the respondents reported that both of their parents are alive while the remaining $12.1 \%$ of the respondents of both parents are died. With regard to their living conditions, 43 (41.3\%) of the participants 


\begin{tabular}{|c|c|c|c|}
\hline \multirow{2}{*}{ Variables } & \multirow{2}{*}{ Alternatives } & \multicolumn{2}{|c|}{ Response (N=104) } \\
\hline & & Frequency & Percentage \\
\hline \multirow{3}{*}{ Before your imprisonment do you have job? } & Yes & 44 & 42.7 \\
\hline & No & 59 & 57.3 \\
\hline & Total & 103 & 100 \\
\hline \multirow{3}{*}{ Was unemployment is the cause of re-offending? } & Yes & 58 & 56.3 \\
\hline & No & 45 & 43.7 \\
\hline & Total & 103 & 100 \\
\hline \multirow{3}{*}{ After released from the first imprisonment, did you have enough income to fulfill your basic necessities? } & Yes & 21 & 20.19 \\
\hline & No & 83 & 79.81 \\
\hline & Total & 104 & 100 \\
\hline \multirow{3}{*}{ Do you think that economic problems were contributed to your reoffending } & Yes & 55 & 59.8 \\
\hline & No & 37 & 40.2 \\
\hline & Total & 92 & 100 \\
\hline
\end{tabular}

Table 3: the contribution of unemployment and other economic factors to recidivism at Dessie and Wodiya correctional centers.

\begin{tabular}{|c|c|c|c|}
\hline \multirow{2}{*}{ Variables } & \multirow{2}{*}{ Alternatives } & \multicolumn{2}{|c|}{ Response $(\mathrm{N}=104)$} \\
\hline & & Frequency & Percentage \\
\hline \multirow{4}{*}{ Parent's Situation } & both parents alive & 43 & 43.4 \\
\hline & both parents died & 12 & 12.1 \\
\hline & one parent died & 44 & 44.4 \\
\hline & Total & 99 & 100 \\
\hline \multirow{6}{*}{ Living condition } & with both biological parents & 28 & 26.9 \\
\hline & with single biological parent & 20 & 19.2 \\
\hline & with step parent/s & 2 & 1.9 \\
\hline & with other relative and/or adult guardians & 11 & 10.6 \\
\hline & Alone & 43 & 41.3 \\
\hline & Total & 104 & 100 \\
\hline \multirow{3}{*}{ Did you grown up by getting love and affection from your families? } & Yes & 57 & 55.3 \\
\hline & No & 46 & 44.7 \\
\hline & Total & 103 & 100 \\
\hline \multicolumn{4}{|c|}{ Source: Own survey, 2017} \\
\hline
\end{tabular}

Table 4: The contribution of living condition and family factors to recidivism at Dessie and Woldiya correctional centers.

were living alone while $28(26.9 \%)$ of the respondents were living with their biological parents. In addition to this, $20(19.2 \%)$ and $11(10.6 \%)$ of the respondents were living with a single biological parent and with relatives and/other adult guardians respectively. Moreover, 57 (55.3\%) of the respondents admitted that they did not grown up by getting love and affection from your families.

This shows that a great deal of recidivists were living with a serious family problems. This might has a serious impact on the overall development and behaviors of recidivists. In substantiated this idea, the qualitative data from interviewee participant's revealed that family socialization affected children's behaviors and attitudes either positively or negatively. Those families who have good characteristics and strong relations were capable to socialize their children's appropriately. In contrary, parent's with anti-social behavior and criminality were also influenced the social, moral, intellectual and personality development of the children negatively. Besides, the perilous kind of child-parental relationship affects the social development of children. This contributes to decrease the quality of relationship between children and parents. In turn, this condition reinforces children's to develop delinquent behaviors, anti-social attitudes, aspirations and practices. In line with this, one of the interviewee from Dessie correctional center narrated his family relationship as follows:
My father was divorced with my mother. Most of the time, I was living with my step mother. I did not get love and affection from both parents. My stepmother told bad things about me to my father. Then, I was quarreled with my father and forced me to leave home and go to the street. I started to live on the street. While in the street, I met with delinquent friends and pressured me to get into theft activities. Then, I imprisoned more than three times for charge of the theft crime [28 years old respondent from Dessie correctional center].

As the respondent above narrates lack of close supervision, lack of emotional attachment, lack of love and affection from parents were the causes of delinquency. Besides, the bad family relationship like conflict is the cause for children's to go to the street and become delinquent. On the street, they were forced to involve into criminal activities either due to peer pressure or to get their basic needs.

The other cause of recidivism was maltreatment of children by their close parents. According to participants, in the rural area most of the rural parent's unknowingly maltreated their children. The maltreatment was done to make their siblings more disciplined. Parents punished their siblings frequently to avoid children's deviant behavior as well as to socialize with appropriate behaviors. The ill-treatment of children by their parents was the causes to aggravate their abnormal behavior. In process, children try to escape and flee to the street. In line 
with the above thought, the following vivid account of the informant will show the effects of maltreatment on children's recidivist behavior:

During the adolescent period I love football. My dad was not permitted to play football. It consider as idleness. When I was played football, my dad punished me frequently. But this might not bring any change in my behavior instead I run off to the town and causes to become recidivist [18 years old informant from Dessie correctional center].

The Impact of Psychological Factors and its Contributing to Recidivism Recidivists were asked whether they experience psychological problems before imprisonment and its contribution for recidivism. As indicated in the above Table 5, 33 (31.7\%) of the respondents reported that they have experienced psychological problems before imprisonment. From a total of 104 recidivists, 19 (18.3\%), 17 (16.3\%), 8 (7.7\%) of respondents were experienced anxiety, depression, and stress respectively. Due to these psychological health problems, the offenders may not respond to any punishment, including imprisonment, rehabilitative programs, or any other measure taken in response to their crime. As such, their tendency to reoffend may continue until their psychological health problems are treated. On the other hand, some of the interviewee has stated role of anti-social personality for their recidivist behavior. The impulsive and aggressive behavior of the individuals also causes to exacerbate their criminal behaviors.

The Impact of Addiction and its Contribution to Recidivism In addition to this, they were asked about drug addiction. Thus, the results shows that $63(60.6 \%)$ of the respondents reported that they had an addiction before imprisonment. Drug addiction can be cause to criminal offense. For this reason and others, drug addiction problems are quite prevalent in the criminal justice population. The majority of the study participants were used to abuse substances, namely, chewing chat, drinking alcohol, smoking cigarette and cannabis during their childhood and adolescence. Similarly, as presented in the above Table 6, 43 (42.6\%), 45 (44.6\%), 42 (41.6\%), 12 (11.9\%) of the respondents had addiction in alcohol, smoking, chewing chat and cannabis. In addition, the respondents were also asked if they have enough income to satisfy their addiction. Indeed, 45 (70.3\%) of the respondents reported that they did not have enough income to satisfy their addiction. As a result, $31(77.5 \%)$ of recidivists admitted that they have committed crime to satisfy their addiction.

It is believed that any type of addiction has a negative impact on behavior of individuals as well as the socioeconomic condition of the family and the society at large. The data from interviewee revealed that drug users are highly exposed to criminal activities because of either motivated by the drug to get money or to meet their addiction. Besides, the high cost of illegal drugs lead users to commit property crimes such as theft, robbery and burglary to get the money to pay for their drugs. In substantiated this idea, interviewee from Dessie correctional center noted that: "if I were not drank alcohol, I was become ill. I also sometimes chew chat. To satisfy my desire or addiction, I was engaged in theft activities. I was generated money via theft" [A 18 year's old interviewee]

\begin{tabular}{|c|c|c|c|}
\hline \multirow{2}{*}{ Variables } & \multirow{2}{*}{ Alternatives } & \multicolumn{2}{|c|}{ Response $(\mathrm{N}=104)$} \\
\hline & & Frequency & Percentage \\
\hline \multirow{2}{*}{ Before imprisonment, did you experience any psychological problems? } & Yes & 33 & 31.7 \\
\hline & No & 71 & 68.3 \\
\hline \multirow{6}{*}{ Types of psychological disorders } & Total & 104 & 100 \\
\hline & Anxiety & 19 & 18.3 \\
\hline & Depression & 17 & 16.3 \\
\hline & Stress & 8 & 7.7 \\
\hline & Suicidal thought and attempt & 8 & 7.7 \\
\hline & Psychotic & 3 & 2.9 \\
\hline
\end{tabular}

Table 5: The psychological condition of recidivists at Dessie and Woldiya correctional centers.

\begin{tabular}{|c|c|c|c|}
\hline \multirow{2}{*}{ Variables } & \multirow{2}{*}{ Alternatives } & \multicolumn{2}{|c|}{ Response $(\mathrm{N}=104)$} \\
\hline & & Frequency & Percentage \\
\hline \multirow{3}{*}{ Before your imprisonment do you have any addiction? } & Yes & 63 & 60.6 \\
\hline & No & 41 & 39.4 \\
\hline & Total & 104 & 100 \\
\hline \multirow{5}{*}{ Types of addiction } & Alcohol & 43 & 42.6 \\
\hline & Smoking & 45 & 44.6 \\
\hline & Chewing chat & 42 & 41.6 \\
\hline & Cannabis & 12 & 11.9 \\
\hline & Others & 3 & 3 \\
\hline \multirow{3}{*}{ Did you have enough income to satisfy your addiction } & Yes & 19 & 29.7 \\
\hline & No & 45 & 70.3 \\
\hline & Total & 64 & 100 \\
\hline \multirow{3}{*}{$\begin{array}{l}\text { If your answer is "No", did you commit any crime to satisfy } \\
\text { your addiction? }\end{array}$} & Yes & 31 & 77.5 \\
\hline & No & 9 & 22.5 \\
\hline & Total & 40 & 100 \\
\hline
\end{tabular}

Table 6: The impact of drug addiction and its contribution to recidivism. 
Cognizant of this, another informant from Dessie correctional centre noted that:

Before imprisonment I am addicted with both alcohol and chat. I chew chat afterward I drink alcohol with no limitation. I always used to drunk. Due to this, I am fighting with other people and compelled to enter the prison repeatedly. In addition, I committed criminal activities to satisfy my desire.

As the study showed that drug addiction has increased the tendency to commit crime. As the qualitative data from respondents revealed that the use of alcohol and chat causes to aggravate recidivist behaviour because addicted people were subjugated to drug or alcohol. The kind of drug or alcohol they were taken stimulated them to get into conflict with others. The conflict that was aroused due to excessive amount of alcohol consumption also causes too many charges and imprisonment. Moreover, they were involved repeatedly in criminal activities to generate funds to buy these drugs. Most of the respondents involved in theft and burglary activities to satisfy their urges. The study also found that using different substance see it as an adventurous act since they had somehow to generate money to satisfy the urge of addiction. This is the most common forms of defies that face the youth in this time.

\section{The impact of labeling and false witness and its contribution to recidivism}

The society labels and stigmatizes the criminal after their term of imprisonment. The released prisoners are labelled as criminals. The findings of the qualitative data revealed that the society and the criminal justice members like police label towards innocents without real evidence. This labeling of inmates by the society as well as by the police is the cause of re offending for many of the inmates. If you imprisoned in theft case, they always consider as thief. This condition forced to react to the label and this is one of the fertile grounds to enter into criminal activities. Besides, the labeled criminals are stigmatized in every governmental, societal and community engagements due their past criminal background. The individuals, families, neighborhoods, communities and other stakeholders have negative attitude towards these released prisoners and they considers as incurable one. They consider as unalterable and will not deter them from future offending.

The other problem is related to false witnes Many people were imprisoned due to false witness. Some police officers were not brought the right criminals. They were criminalized people based on their background history without tangible evidences. If you have a criminal record, some community police officers also imprisoned individual due to their conflict of interest. To do this, they were provided false witness. Based on false witness provided, they were forced to serve your life in prison. No one was volunteered to hear the voice of the prisoner since once they have labeled as criminals. This condition has negative outcomes on the long last life of the so called criminals. As a result, some inmates were imprisoned for the first time on false witness but gradually they become recidivist. In corroborate of this idea, 18 years of old key informant told his story as follows:

I came for the first time from the rural area to attend my high school education but I did not able to continue my education further due to economic problems. My family could not support me to continue my education. Then, I decided to work as tax conductor (Redat) to support myself. My work is always on the night time. One day when I was return from work, my neighbor accuses me with theft crime. This case forced me to get imprisonment for the first time. Then, the court charges me with two months on false witness (Adafiniye). After serving this, I had also imprisoned for second times. However, I did not commit the first and the second crimes. I had only committed the third one but my neighbor accused and imprisoned me for two times by providing false witness. I only committed the third crime even so I have imprisoned around two year for all of the three cases.

\section{Lack of classification and overcrowding of correctional cen- ters and its contribution to recidivism}

In both Dessie and Woldiya correctional centers there were no separate accommodation based on age, type and seriousness of crime. Therefore, there is no separate accommodation for prisoners based on the law ratified by Council of Ministers. Thus, lack of classification system of prisoners based on their age, types of crimes, recidivists and indecent prisoners are the causes for re offending of inmates. So in both prison all inmates are lumped together in one cell. This enables minor offenders to share experience from their seniors. Lack of classification between long term and sort term prisoners causes to share experience. The long term inmates were thought juveniles and minor offenders on how to escape from law after committing crime. Further, Prisoners' intense and intimate communications were cause to be taught all criminal act techniques.

Furthermore, Ethiopian prisons suffered from over-crowdedness and lack of adequate sanitation. Prison facilities have not been expanding with the increase in crime. As a result, most prisons were overcrowded. In the dormitories each prisoner was allotted very narrow sleeping space. The two correctional centers are getting overcrowded by increasing the number of the prisoners. In support of this, key informant from Woldiya correctional centre noted that:

All prisoners were imprisoned together due to this, all cells were overcrowded. In the absence of space, proper classification of inmates was impossible. As a result, I have shared the story of habitual criminals and the different criminal techniques, motives and intention inside the prison. Crime is considered as adventure rather than evil deed. This condition increases the tendency of the criminal like me to commit crime after release [33 years interviewee from Woldiya correctional center].

The overcrowding nature of rooms causes prisoners to make an interaction to each other. In process, the first time offenders make association with other hardens criminals thus causes to learn criminal behavior. The overcrowding nature of the correctional space evokes the prisoners to train each other. Then, amateurs turn into professional criminals.

\section{The impact of peer pressure and its contribution to recidivism}

The findings of the qualitative data showed that peer pressure and influence is the causes of recidivism. Most of the recidivists had delinquent friends during their childhood and adolescence. The association with delinquent peers causes to the utilization of addictive substances like alcohol, chat, cigarette and cannabis in turn contribute towards their initial involvement in criminal activities. It also showed that recidivists addiction problem coupled with delinquent peer's pressure had influenced them to commit further crime. The story of the informants from Woldiya correctional centre supports this idea which has stated as follows "I was living with delinquent juveniles on the street. In the process, I learned delinquent behavior from my friends. First I used to chew chat and smoking cigarettes. Next, I learned gambling and theft techniques to satisfy my addiction as well as to sustain my life". Another interviewee from Dessie correctional center stated that "I have both good and bad friends. Those bad friends had the propensity to commit crime. They have committed crime in group. Finally, I have joined the bad groups and engaged different types of crime. This evil action cause to serve more than five times inside the custody". 


\section{The impacts of short imprisonment on recidivists tendency to commit crime}

The majority inmates were imprisoned for theft crimes which come up with short term imprisonments. This short term imprisonment has minimum capacity to deter further re- offending of criminals. Besides, in a short period of time it is difficult to bring behavioral changes. Thus, the intended goals of rehabilitation program did not achieve its goals in modifying the behavior of short term prisoners instead they serve as a breeding place of crime. That means with a short period of time, prisoners learn different criminal behaviors.

\section{Reintegration challenges and its contribution to recidivism}

Reintegrating inmates after they have released from correctional centers should be one of the core mission of correctional centers and other concerned governmental and non-governmental organizations however this issue had become challengeable due to different factors. Many of the ex-prisoners are confronted by a range of social, economic, psychological and personal problems that tend to significantly complicate their social reintegration. Some of those challenges result from the offenders' personal difficulties and past criminal history. Other challenges are the direct consequence of imprisonment and the community's negative attitude towards released prisoners.

As indicated above Table 7, a great proportion of prisoners 55 (52.9\%) reported that they have experienced reintegration problems after their release. This occurs because of discrimination and marginalization (34.3\%), not having financial and material supports (31.3\%), no job opportunities (22.2\%), do not have families and relatives (12.1\%). In line with this finding, 98 (94.2\%) of the recidivists reported that they did not get any material and financial support from concerned bodies after they finished their time in prison.

Similarly, the qualitative data from respondents also showed that life after prison was difficult to adjust to the outside social environment. The outside social environment is not favorable for released prisoners due to absence of social and economic support to reintegrate with the community. This makes to become hopeless. The general public as well as the police stigmatized even though they reformed. The society have developed negative attitude towards these released prisoners. They were not wanted to approach as well as interact to them. Most of the communities decide to ignore them. No one trusts them even though they were brought attitudinal and behavioral changes. Hence, the existing stigma and marginalization by the general population compelled them to make an association with other criminals and to reoffend many times. Therefore, stigma and discrimination has impacted the relationships of inmates with family members, relatives and friends. It also affects inmate families. They were stigmatized by their neighbors and their other acquaintances. The recidivist's families were victims of their misdeeds, being maligned in formal and informal social gatherings.

As the above shows almost all prisoners face a range of difficulties during post-release reintegration. The quantity and quality of resources as well as the kinds of attention given for released prisoners are generally very insufficient. The study found that prison authorities could not provide any financial help upon release for transportation and other accommodation costs. Released prisoners also lacked basic needs such as food, shelter and clothing. Such problems were forced them to be involved in criminal acts like theft and robbery.

The study also found that there is no any partnership and collaboration between prison authorities and other government and non-government organizations to attend the ex-prisoners. As a result, there are no any post-release support services due to the absence of working group to assist prisoners' to prepare for release and to link prison preparation with social and health services outside prison. No one tried to offer any training to released prisoners. The psychologists and social workers as well as the correctional center have not any role to attend the ex-prisoners. There is no a comprehensive mechanism that was created to address the social, economic and psychological needs of the individual prisoners. This causes to an increase in the number of re offenders.

\section{Discussion}

Sex has always been a strong determinant of criminal activities. Sex differences in crime are distinctions between men and women as perpetrators of crime [16]. Findings in Ghana shows that $91.2 \%$ of the recidivists sampled were males while only $8.8 \%$ are females [17]. Similarly, this study also indicated that $96.2 \%$ and $3.8 \%$ were males and females respectively. This shows that more men commit crime than women do. Age is another strong determinant of crime [17]. The respondents' age ranged from 16 years to 64 years with the mean age of 24.27 years. Therefore, $84 \%$ of the respondents were found $16-29,13 \%$ were found 30-43 while the rest $3 \%$ were above the age of 44 . Recidivism rates decline relatively consistently as age increases [18]. This implies that the younger the offender, the more likely the offender recidivates. In this study, $69.6 \%$ of the respondents came from urban areas while the remaining $30.4 \%$ of the respondents were from rural areas. On the other hand, study in Addis Ababa on the causes of juvenile delinquency

\begin{tabular}{|c|c|c|c|}
\hline \multirow{2}{*}{ Variables } & \multirow{2}{*}{ Alternatives } & \multicolumn{2}{|c|}{ Response $(\mathrm{N}=104)$} \\
\hline & & Frequency & Percentage \\
\hline \multirow{3}{*}{ After release, did you experience any reintegration challenges? } & Yes & 55 & 52.9 \\
\hline & No & 49 & 47.1 \\
\hline & Total & 104 & 100 \\
\hline \multirow{5}{*}{ If you say yes, what were the major reintegration challenges? } & No material and financial support & 33 & 31.3 \\
\hline & Discrimination and marginalization & 34 & 34.3 \\
\hline & No family or relatives to go & 12 & 12.1 \\
\hline & Do not have opportunity to get job & 22 & 22.2 \\
\hline & Others (Specify) & 3 & 2.9 \\
\hline \multirow{3}{*}{$\begin{array}{l}\text { Did you get material and financial support from concerned } \\
\text { bodies after you finished your time in prison? }\end{array}$} & Yes & 6 & 5.8 \\
\hline & No & 98 & 94.2 \\
\hline & Total & 104 & 100 \\
\hline
\end{tabular}

Table 7: Reintegration challenges at Dessie and Woldiya correctional centers. 
by Sisay [19] found that $53.49 \%$ were came from Addis Ababa and other urban areas in Ethiopia while the rest of the respondents were from rural area in Ethiopia. Another study in west of Guilan by Sanei and Khalili [20] found that $57 \%$ of the respondents were from the rural area whereas $43 \%$ were from the city. The other determinant factor for recidivism is educational level of the prisoners. Accordingly, the study shows that $26.0 \%$ of the respondents were illiterate. Similarly study in Ghana by Antwi [17] revealed that 20.6 of the respondents were illiterate. In addition to this, $16.3 \%, 26.0 \%$ and $28.8 \%$ of the respondents were learned from 1-4, 5-8 and 9-12 grades respectively. Sisay [19] in his study in Addis Ababa found that $18.60 \%, 55.81 \%$ and $2.33 \%$ were learnt 1-4, 5-8 and 9-10repectively. Moreover, studies in US shows that offenders with less than a high school education are most likely to recidivate $(31.4 \%)$, followed by offenders with a high school education (19.3\%), offenders with some college education (18.0\%), and offenders with college degrees (8.8\%).

The findings of the quantitative data revealed that the majority of respondents $74.5 \%$ were married. The remaining $20.6 \%$ and $4.9 \%$ of the respondents were single and divorced respectively. However, findings in Ghana not in favor of the above finding. According to the finding in Ghana $14.7 \%$ were married, $29.4 \%$ were single and the rest $38.3 \%$ of the respondents were divorced. This indicates that lack of a marital relationship by most of the offender's leads to criminal persistence in Ghana [17], but in this study the majority recidivists were married ones. Another important indicator for understanding the socioeconomic status is the monthly income of the respondents. Accordingly, $47.1 \%$ and $32.7 \%$ of the respondents had a monthly income of below 500 birr and between 500 and 1000 birr respectively.

Findings from quantitative data shows that $68.3 \%$ of the respondents were reoffend two times, $22.1 \%$ were reoffend three times and $7.7 \%$ were reoffend four times. The remaining 1.9 were reoffended more than five times. Studies in west of Guilan by Sanei and Khalili [20] found that 42 percent of prisoners had 2 criminal records, 36 percent had 3, 18 percent had 4, and 4 percent had more than 5 criminal records. Another study in Ghana shows that $94.1 \%$ have acquired the criminal label for at least two times while $5.9 \%$ of the participants have been to prison three times. In addition to this, $58.1 \%$ and $19.2 \%$ of the study respondents were convicted theft and assault crime respectively. Similarly, the qualitative data from participants indicates that the most common types of crime committed by recidivists were property crime like theft, burglary and fraud. Followed by assault and bullying. But studies in west of Guilan shows that all crimes committed by 37 percent of them were on drugs whereas all crimes committed by 31 percent of them were robbery. Committed crimes of 35 percent of them were different such as assaults and divergent, financial, dowry, accident and alcoholic drinks and etc. [20].

Economic or material deprivation is one among the factors that throw in to crime. This also considered as factors for re-offending. The economic problems of the participants were manifested in the form of unemployment, poverty and lack of income which leads people to engage in criminal activities repeatedly. Therefore, the quantitative data revealed that $57.3 \%$ of the respondents were unemployed before their imprisonment; and $56.3 \%$ of the respondents believed that unemployment was the causes of re-offending. The other, $59.8 \%$ of the respondents admitted that economic problems contributed to their reoffending. Similarly, literature shows that for a person to commit a property crime the primary cause may probably be his poverty. It suggests that criminal behavior will occur when a person feels in some way materially deprived, whether by poverty or unemployment [21].
Another study conducted by Omboto [22], indicated that most of the offenders are in crime because of poverty, which drove them into the criminal acts for survival. The finding of this study on poverty as a cause of crime confirms the opinion of Omboto [22]. However, study by Omboto [22] not tried to show the findings in quantity. Besides, this study also tries to address the economic segregation and marginalization of prisoners in the post release periods and its negative consequences such as lack trust and lack of financial assistance/loans to establish their own business.

The other contributing factor to recidivism were living condition and family factors. Hence, $56.5 \%$ of the respondents reported that one of their parents (either mother or father) or both parents are died whereas $43.4 \%$ of the respondents reported that both of their parents are alive. Correspondingly, studies in west of Guilan showed that the families of 56 percent of prisoners had been torn apart by the loss of a parent or a person [20]. Additionally, $41.3 \%$ of the participants were living alone while $26.9 \%$ of the respondents were living with their biological parents. The rest $19.2 \%$ and $10.6 \%$ of the respondents were living with a single biological parent and with relatives and/other adult guardians respectively. This revealed that the majority of the recidivists were living alone which lead to children to delinquent actions. According to Gibbons (1992) delinquents tends to come from homes characterized by family members who are criminal, delinquent or alcoholic, absence of one or both parents through divorce, desertion, or death and lack of parental control The offenders were more commonly from homes in which the parents had histories of series physical ailments, mental retardation, drunkenness of criminality. In substantiating this, the finding shows that lack of close supervision, lack of emotional attachment, lack of love and affection from parents and maltreatment were the causes of delinquency. Besides, the bad family relationship like conflict is the cause for children's to go to the street and become delinquents.

The data from the survey indicates that $31.7 \%$ of the respondents experienced psychological problems before imprisonment. The major psychological problems experienced by recidivists were anxiety, depression, and stress consists of $18.3 \%, 16.3 \%$, and $7.7 \%$ respectively. Moreover, impulsive and aggressive behavior of the individuals also causes to exacerbate their criminal behaviors. In line with this finding, Hanson and Morton-Bourgon [23] find that anti-social orientation is a major predictor of violent and general recidivism. Anti-social orientation refers to anti-social traits including impulsivity, characterogical defects and substance abuse. The other contributing factor to recidivism is drug addiction. For this reason and others, drug addiction problems are quite prevalent in the criminal justice population. The majority of the study participants were used to abuse substances, namely, chewing chat, drinking alcohol, smoking cigarette and cannabis during their childhood and adolescence. Similarly, as presented in the above Table $6,42.6 \%, 44.6 \%, 41.6 \%, 11.9 \%$ of the respondents had addiction in alcohol, smoking, chewing chat and cannabis. Indeed, $70.3 \%$ of the respondents did not have enough income to satisfy their addiction. Thus, $77.5 \%$ of recidivists admitted that they have committed crime to satisfy their addiction. The data from interviewee revealed that drug users are highly exposed to criminal activities because of either motivated by the drug to get money or to meet their addiction. Sisay [19] in his study of juveniles delinquency in Addis Ababa found that chat and alcohol are the widely used drugs among the delinquents $67.44 \%$ for each followed by cigarette, hashish, benzene, shisha $65.11 \%$, $18.60 \%, 15.11 \%$ and $12.80 \%$ respectively. Having engaged in different habit has a proofing effect on their behavior and forced them to involve in deviant acts as well as to be dependent to their parents. Likewise, the 
data from interviewee revealed that drug users are highly exposed to criminal activities because of either motivated by the drug to get money or to meet their addiction. Besides, the high cost of illegal drugs lead users to commit property crimes such as theft, robbery and burglary to get the money to pay for their drugs.

Labeling Theory reveals that ex-convicts face the labeling and the stigma of the criminal justice system and society, and hence a lack of access to education and employment. The theory attempts to explain crime as a social phenomenon. It explains how criminal careers are based on destructive social interactions and encounters [24]. The theory conceives deviance and conformity as being the results, not so much of what people do, as of how others respond to those actions; and hence it highlights social responses to crime and deviance as the principal causal element. Labeling not only transforms a person's identity but also his or her social relationships. The theory asserts that if a devalued status is conferred by a significant other teacher, police officer, parent, or valued peer, the negative label permanently harm the target [25]. In line with this theoretical argument, the released prisoners are labeled as criminals thus societal labels and stigmatization causes to re offending. The findings of the qualitative data revealed that the society and the criminal justice members like police label towards innocents without real evidence. This labeling of inmates by the society as well as by the police is the cause of re offending for many of the inmates. Besides, the labeled criminals are stigmatized in every governmental, societal and community engagements due their past criminal background. The other problem is related to false witness. Many people were imprisoned due to false witness. They were criminalized people based on their past background history without tangible evidences. This condition has negative outcomes on the long last life of the so called criminals.

According to Federal Negarit Gazeta No. 47 [26], prisoners on death roll shall be separately accommodated from other prisoners. In the same way, in sub section of this article, it also stated that juvenile prisoners under the age of 18 and persons detained upon judicial remand shall have separate accommodations from convicted prisoners. Besides, prisoners with records of serious crimes, recidivists and indecent prisoners shall have separate accommodations from other prisoners. However, in both prison this laws are not practical applicable. Findings showed that there is lack classification in both prison except for females; and it overcrowding nature of the correctional center causes prisoners to share their experience specifically amid short term, long term and remand prisoners. The long term inmates were thought juveniles and minor offenders on how to escape from law after committing crime. Further, Prisoners' intense and intimate communications were cause to be taught all criminal act techniques. In process, the first time offenders make association with other hardens criminals thus causes to learn criminal behavior. The overcrowding nature of the correctional space evokes the prisoners to train each other. Then, amateurs turn into professional criminals. In confirming this, the report of Ethiopian human Rights Commission [27] shows that most detention centers do not have separate accommodations on the basis of offences, type of sentence, age and adjournment as required by law. Therefore, the joint imprisonment of juveniles with adult prisoners causes to re offending.

The findings of the qualitative data showed that peer pressure and influence is the causes of recidivism. Most of the recidivists had delinquent friends during their childhood and adolescence. The association with delinquent peers causes to the utilization of addictive substances like alcohol, chat, cigarette and cannabis in turn contribute towards their initial involvement in criminal activities. It also showed that recidivists addiction problem coupled with delinquent peer's pressure had influenced them to commit further crime. Studies conducted by Warr [28] reinforces the above findings, juveniles who mix with delinquent peers are more at risk of involvement in crime simply because delinquents communicate deviant attitudes and values. He suggests that, association with delinquent peers has an influence on crime. On the other hand, the majority inmates were imprisoned for theft crimes which come up with short term imprisonments. This short term imprisonment has minimum capacity to deter further re- offending of criminals as well as it is difficult to bring behavioral changes among prisoners. Thus, the intended goals of rehabilitation program did not achieve its goals in modifying the behavior of short term prisoners instead they serve as a breeding place of crime. That means with a short period of time, prisoners learn different criminal behaviors.

Reintegrating inmates after they have released from correctional centers should be one of the core mission of correctional centers and other concerned governmental and non-governmental organizations however this issue had become challengeable due to different factors. As result, $52.9 \%$ of the respondents experienced reintegration problems after their release. Among the challenges, 34.3\% were due to discrimination and marginalization, $31.3 \%$ due to lack of financial and material supports, $22.2 \%$, were no job opportunities; and rest $12.1 \%$ does not have families and relatives. In line with this finding, $94.2 \%$ of the recidivists reported that they did not get any material and financial support from concerned bodies after they finished their time in prison. Besides, the qualitative data from respondents also showed that life after prison was difficult to adjust to the outside social environment. The outside social environment is not favorable for released prisoners due to absence of social and economic support as well as the existing societal stigma and discrimination towards exprisoners this makes reintegration challengeable [29]. The other factors that affect reintegration process were the dearth of resources and lacks of attention for released prisoners. Finally, the absence of partnership and collaboration between prison authorities and other government and non-government organizations causes to re offending.

\section{Conclusion and Recommendation}

\section{Conclusion}

This study closely examines the factors causing inmates to reoffend, the most common crimes committed by recidivists, lived and post prison experiences of the prisoners, and the rehabilitation and reintegration services offered by the prison centers and governmental organizations to reintegrate the recidivists socially and economically to their home community upon release. Therefore, the finding of this study indicates that most of the prisoners committed crime more than two times. The most common types of crimes committed by recidivists were theft and assault and most of the recidivists were convicted by the same crime at the second, third and fourth time [30].

Additionally, the findings of this study reveals that the main contributing factors for recidivism were economic problems like poverty, lack of income, unemployment and poor living conditions, because this study found that most of the prisoners do not have job and enough income before and after imprisonment. Besides, family problems like lack of close supervision and guidance, lack of love and affection from parents, divorce or separation, and death of one or both parents are other pushing factors for recidivists to re-offend. Moreover, the current study indicates those psychological problems (i.e. anxiety, depression, addiction, aggressive personality traits) and labeling, discrimination and marginalization, false witness and peer pressure are the main causes of re-offending [31]. Lack of classification and over 
overcrowding of correctional centers, lack of adequate rehabilitation and reintegration services are other factors contributing for recidivism.

In conclusion, the majority of recidivists have economic, family, psychological problems before and after imprisonment. They do not receive reintegration trainings and assistances by concerned bodies. Besides, they were discriminated and marginalized by the community and government officials especially by security personnel and judges. Thus, the majority of recidivists were not effectively reintegrated after imprisonment. Consequently, it is assumed that these bad situations forced many of the recidivists to re-offend.

\section{Recommendations}

This research recommends to designing an effective, efficient and sustainable socio-economic reintegration system for recidivists upon release by actively participating recidivists, families of recidivists, community, government as well as nongovernmental organizations in the process of reintegration. Recidivists have different socio-economic, psychological, rehabilitation challenges that affect their reintegration processes. Consequently, these challenges are pushing factors for reoffending. Based on the findings, the following recommendations are forwarded:

The study specified that the community, security personnel's and judges mistreated, discriminated and marginalized recidivists. Since they have record of crime they convicted them by false witness. Therefore, national awareness creation programs should be launched through mass media to shape the negative perception of community towards criminals, and tackle the convoluted challenges that recidivists faced in the community. It is also recommended that non-governmental organizations should be organizing and working jointly with the government especially with the police and justice system to alleviate negative perception of community towards criminals and secure their social existence within home community.

The government should reassess the rehabilitation services and treatment of inmates in the correctional centres. The prison centres, governmental and nongovernmental organizations should provide reintegration trainings and assistance for recidivists. Specifically, the government should create job opportunities and provide financial assistance for released prisoners to effectively reintegrate to the society. Additionally, policy makers should create appropriate policy frame which can address the current gaps in the treatment of prisoners. Besides, the policy the framework should specify the role of families, the community and the government as well as non-governmental organizations in the successful and sustainable reintegration of recidivists.

The counsellors nd social workers in the prison centres should provide sufficient counselling services to recidivists to treat their psychological problems. Besides, they should provide reintegration trainings, vocational and financial management skill trainings for recidivists before release. This helps recidivists to improve their reintegration with home community.

Governmental, nongovernmental organizations and other stakeholders should work on family development to reduce family problems like conflict, separation, divorce, death of parents.

The study suggests that the government and non-governmental organizations should launch effective discussion and training programs with various stakeholders such as; local administrators, land administrators, trade authorization officers and others, to equip them with the reintegration supports that they should offer for recidivists
, and correct their wrong work ethics to secure recidivists access to local resources , and sustainably reintegrating them economically and socially within home community.

\section{References}

1. National Institute of Justice (2010) Recidivism.

2. Council of Juvenile Correctional Administrators (2009) Defining and measuring recidivism. CJCA White Paper. Braintree, MA: Council of Juvenile Correctional Administrators.

3. Benda BB (2005) Gender Differences in Life-Course Theory of Recidivism: A Survival Analysis. Int J Offender Ther Comp Criminol 49: 325-342.

4. Sampson RJ, Laub HJ (2001) Understanding Desistance from Crime. Crime and Justice 28: 1-69.

5. Solomon AL, Johnson KD, Travis J, Mcbride EC (2004) From prison to work The employment dimensions of prisoner reentry. A report of the Reentry Roundtable, The Urban Institute, Washington DC.

6. Austin J, Hardyman PL (2004) The Risks and Needs of the Returning Prisoner Population. RPR 21: 13-29.

7. Gibbons CD (1992) Society, crime and criminal Behavior (6thedn) PrenticeHall, New Jersey,

8. Tesfaye A (2004) The Crime Problem and Its Correction. Addis Ababa: Addis Ababa University Press, Euthopia.

9. Daniel W (2004) Crime Incidences in Addis Ababa with an Emphasis on the Nature Spatial Pattern, Causes, Consequences and Possible Remedies (MA. Thesis). Addis Ababa University, Ethiopia.

10. Nayak BK (2013) Juvenile Delinquency: Its Magnitude and Impact at Gondar Town in Ethiopia. IJMSSR 2: 14-21.

11. Meti K (2016) An Assessment of Socio-Economic Factors on Crime: A Case Study of Kaliti Correctional Administration, Addis Ababa University, Ethiopia

12. Dessie Town Administration Office Magazine (2009).

13. Ministry of Urban Development and Construction (2010)

14. Creswell, John W (2009) Research Design: Qualitative Quantitative, and Mixed Methods Approaches (3rdedn), Los Angeles, United States of America: SAGE Publications.

15. Kothari CR (2004) Research methodology: Methods and techniques (2ndedn), New Age International, New Delhi, India.

16. Siegel LJ (1998) Criminology. Wadsworth Publishing Company, NY.

17. Antwi A (2016) Social Reintegration of Offenders and Recidivism in Ghana University of Ghana.

18. U.S. Sentencing Commission (2014) Measuring Recidivism: The Criminal History Computation of the Federal Sentencing Guidelines. A Component of the Fifteen Year Report on the U.S. Sentencing Commission's Legislative Mandate.

19. Zegeye S (2016) Causes of Juvenile Delinquency; A Case of Lideta SubCity Administration Remand and Rehabilitation Center of Addis Ababa. Addis Ababa University, Ethiopia.

20. Sanei M, Khalili M (2015) Factors affecting recidivism and return to prison male prisoners in the prisons of the west of Guilan and strategies for prevention. JSRAD 2: 156-16.

21. Feldmen $P$ (1993) The psychology of crime. Cambridge University press, UK.

22. Omboto JO (2010) Challenges Facing the Control of Drugs and Substances Use and Abuse in Prisons in Kenya: The case of Kamiti Prison. University of Nairobi, Kenya.

23. Hanson RK, Morton-Bourgon KE (2005) The Characteristics of Persisten Sexual Offenders: A Meta-Analysis of Recidivism Studies. J Consult Clin Psychol 73: 1154-63.

24. Brown S, Esbensen F, Geis G (2010) Criminlogy: Explaining Crime and its Context. New Jersey: Matthew Bender and Company.

25. Macionis J, Plummer K (2007) Sociology: A Global Introduction (4thedn) Pearson Education Limited, England. 
Citation: Tegeng G, Abadi H (2018) Exploring Factors Contributing to Recidivism: The Case of Dessie and Woldiya Correctional Centers. Arts Social Sci J 9: 384. doi: 10.4172/2151-6200.1000384

Page 12 of 12

26. Federal Negarit Gazeta of the Federal Democratic Republic of Ethiopia $13^{\text {th }}$ year (2007) 47. Addis Ababa, Ethiopia.

27. EHRC (2012) Human Rights Protection Monitoring in Ethiopian Prisons Primary Report. Addis Ababa, Euthopia.

28. Warr M (1998) Life-course Transitions and Desistance from Crime. Criminology 36: $183-216$.
29. United Nation Office on Drug and Crime (2012) Introductory Handbook on the Prevention of Recidivism and the Social Reintegration of Offenders. New York, USA.

30. Glaeser EL (1999) An Overview of Crime and Punishment. Harvard University and NBER.

31. Kumar R (2011) Research Methodology a step-by-step guide for beginners (3rdedn), SAGE Publications Ltd, Los Angeles. 